\title{
Correction to: Epidemiology of Injury and Illness Among Trail Runners: A Systematic Review
}

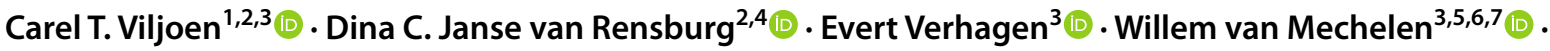

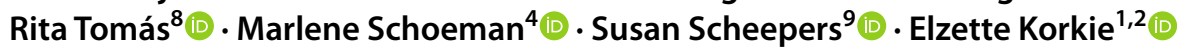

Published online: 21 August 2021

(c) Springer Nature Switzerland AG 2021

\section{Correction to: Sports Medicine (2021) 51:917-943 https://doi.org/10.1007/s40279-020-01418-1}

On 17 March 2021, an erratum was published online [1] in the International Journal of Sports Medicine that showed corrected values for the incidences of injury and illness presented in the Vernillo et al. study [1]. The Vernillo et al. study was included in our systematic review[2] and therefore the following updates should be applied:

\section{Abstract}

The sentence describing incidence range previously read:

"The overall incidence range was 1.6-4285.0 injuries per $1000 \mathrm{~h}$ of running and $65.0-6676.6$ illnesses per $1000 \mathrm{~h}$ of running."

Updated to read:

The original article can be found online at https://doi.org/10.1007/ s40279-020-01418-1.

Carel T. Viljoen

carel.viljoen@up.ac.za

1 Department of Physiotherapy, Faculty of Health Sciences, University of Pretoria, Pretoria, South Africa

2 Sport, Exercise Medicine and Lifestyle Institute (SEMLI), Hillcrest Campus, University of Pretoria, Burnett Street, Hatfield, Pretoria 0002, South Africa

3 Amsterdam Collaboration for Health and Safety in Sports, Department of Public and Occupational Health, Amsterdam Movement Sciences, Amsterdam University Medical Centers, Location VU University Medical Center, Amsterdam, The Netherlands

4 Section Sports Medicine, Faculty of Health Sciences, University of Pretoria, Pretoria, South Africa
The overall incidence range was 1.6-61.2 injuries per $1000 \mathrm{~h}$ of running and 65.0-95.4 illnesses per $1000 \mathrm{~h}$ of running.

Table 2:

Below the "Incidence/Prevalence" column of the Vernillo et al. (2016) row, the injury rate per $1000 \mathrm{~h}$ previously read:

"Injury rates per $1000 \mathrm{~h}(90 \% \mathrm{CI})$ : MSK ${ }^{\mathrm{a}}$ : 4285.0 (3899.35313.4) Skin: 2192.3 (1994.9-2718.4)”

Updated to read:

Injury rates per $1000 \mathrm{~h}(90 \% \mathrm{CI})$ : $\mathrm{MSK}^{\mathrm{a}}{ }^{\mathrm{a}} 61.2(48.0-78.1)$ Skin: 31.3 (22.2-44.2).

Table 3:

Below the "Incidence/Prevalence" column of the Vernillo et al. (2016) row, the illness rate per $1000 \mathrm{~h}$ previously read:

"Illness rates per $1000 \mathrm{~h}(90 \% \mathrm{CI})$ : Medical: 6676.6 (6075.7-8278.9)"

5 School of Human Movement and Nutrition Sciences, Faculty of Health and Behavioural Sciences, University of Queensland, Brisbane, Australia

6 Division of Exercise Science and Sports Medicine (ESSM), Department of Human Biology, Faculty of Health Sciences, University of Cape Town, Cape Town, South Africa

7 School of Public Health, Physiotherapy and Population Sciences, University College Dublin, Dublin, Ireland

8 Portugal Football School, Portuguese Football Federation, Lisbon, Portugal

9 Department of Library Services, Faculty of Health Sciences, University of Pretoria, Pretoria, South Africa 
Updated to read:

Illness rates per $1000 \mathrm{~h}(90 \% \mathrm{CI})$ : Medical: 95.4 (78.8-115.5)

\section{Conclusion:}

The concluding sentence previously read:

"Our review showed that, injury and illness are common among trail runners with an overall incidence range of 1.64285.0 injuries per $1000 \mathrm{~h}$ of running and 65.0-6676.6 illnesses per $1000 \mathrm{~h}$ of running."

Updated to read:
Our review showed that, injury and illness are common among trail runners with an overall incidence range of 1.661.2 injuries per $1000 \mathrm{~h}$ of running and 65.0-95.4 illnesses per $1000 \mathrm{~h}$ of running.

\section{References}

1. Vernillo G, Savoldelli A, La Torre A, Skafidas S, Bortolan L, Schena F. Injury and illness rates during ultratrail running. Int $\mathbf{J}$ Sports Med. 2016;37(7):565-9. https://doi.org/10.1055/s-00351569347.

2. Viljoen CT, van Rensburg DCJ, Verhagen E, van Mechelen W, Tomás R, Schoeman M, et al. Epidemiology of injury and illness among trail runners: a systematic review. Sports Med. 2021. https://doi.org/10.1007/s40279-020-01418-1. 